\title{
LA ÉTICA EN LA AUDITORÍA
}

Alan Errol Rozas Flores*

En el complejo y complicado mundo del tercer milenio, en el que el fenómeno de la corrupción está incrementándose peligrosamente, muchos sectores de la sociedad apelan a la Ética como uno de los mecanismos más importantes de lucha anticorrupción.

¿Por qué la gente actúa en forma no ética? Generalmente la gente actúa en forma no ética, debido a dos razones principales:

porque los principios éticos de una persona difieren de los de la sociedad en general,

porque la persona decide actuar con egoísmo.

¿Y cuáles son las disculpas más comunes para ello?

porque todo el mundo lo hace, porque si es legal, entonces es ético, porque es improbable que se descubra, dado que no tendrá consecuencias importantes.

\section{DILEMAS ÉTICOS}

Con frecuencia las personas debemos resolver rápidamente los dilemas éticos que nos presenta la vida moderna. Un dilema ético es una situación que enfrenta una persona, y en la cual toma una decisión sobre la conducta adecuada o apropiada. Generalmente, los dilemas éticos comprenden situaciones en las cuales el bienestar de uno o de más individuos se ve afectado por los resultados de la decisión.
Los dilemas éticos a los cuales se enfrentan los auditores frecuentemente tienen un efecto sobre el bienestar de un número de individuos o grupos. Por ejemplo, si un auditor toma una decisión carente de ética sobre el contenido de un informe de auditoría, el patrimonio de miles de inversionistas y de acreedores puede verse afectado.

Los dilemas éticos que se presentan con mayor frecuencia dentro del ejercicio de la profesión de contador público como de la auditoría, están vinculados con los aspectos siguientes:

a) Competencia profesional

b) Responsabilidad individual y asociación de profesionales

c) Cuidado y diligencia profesional

d) Control de calidad

e) Objetividad profesional

f) Consultoría tributaria

g) Recursos del cliente

h) Confidencialidad

i) Honorarios y comisiones

j) Publicidad y promoción

k) Solicitudes de clientes, etc.

¿Cómo hacer para solucionar los dilemas éticos? Diversos marcos de referencia han sido propuestos para solucionar los dilemas éticos; sin embargo, el más recomendado y utilizado es el marco de referencia general para la toma de decisiones, que consiste en seguir los pasos siguientes: 
1. Identificar el problema.

2. Identificar cursos de acción posibles.

3. Identificar las limitaciones relacionadas con la decisión.

4. Analizar los efectos probables de los cursos de acción posibles.

5. Seleccionar el mejor curso de acción.

\section{LA ÉTICA PROFESIONAL}

La ética profesional es una parte de la ética, que estudia los deberes y los derechos de los profesionales. Puede ser conceptualizada desde dos puntos de vista:

a) Desde el punto de vista especulativo (analiza los principios fundamentales de la moral individual y social, y los pone de relieve en el estudio de los deberes profesionales).

b) Desde el punto de vista práctico (establece a través de normas o reglas de conducta, el orden necesario para satisfacer el bien común).

Según Alvin A. Arens: "la sociedad ha atribuido un significado especial al vocablo profesional, en el sentido que debe esperarse que un profesional se comporte a un nivel superior que otros miembros de la sociedad. Por ejemplo, cuando los periódicos informan que se acusa de un delito a un médico, a un sacerdote, un congresista o un contador público, la gente se siente más decepcionada que cuando ese mismo tipo de cosas suceden con gente que no tiene la etiqueta de profesionales".

El Josephson Institute for the Advancement of Ethics, es un instituto creado como una fundación no lucrativa con el propósito de fomentar la conducta ética de los profesionales del sector gobierno, del derecho, la medicina, los negocios, la contabilidad y el periodismo, ha desarrollado un interesantísimo conjunto de principios éticos que se muestran a continuación:

\section{Principios Éticos Prescritos}

1. Honestidad

Sé veraz, sincero, franco, honrado, imparcial; no digas mentiras, robes, engañes, o embauques a la gente ni seas tortuoso.

2. Integridad

Sé una persona de principios, honorable, recta, valerosa, y actúa de acuerdo a tus convicciones; no seas falso o sin escrúpulos, ni adoptes la filosofía del fin justifica los medios que ignora todo principio.

3. Cumplimiento

Sé digno de confianza, cumple tus promesas, tus compromisos, cumple con la esencia y la letra de un convenio; no interpretes los convenios en una forma irrazonablemente técnica y legalista para racionalizar el incumplimiento o crear excusas y justificaciones para romper un compromiso.

4. Lealtad (fidelidad)

Sé fiel y leal a la familia, amigos, empleadores, clientes y a tu país; no utilices ni reveles información que obtuviste en forma confidencial; en un contexto profesional, cuida tu capacidad de hacer juicios profesionales independientes evitando con escrúpulo cualquier influencia indebida y los conflictos de interés.

5. Imparcialidad

Sé justo y razonable, dispuesto a admitir el error y, cuando sea adecuado, a cambiar de posición y creencias, demuestra un compromiso con la justicia, el trato igual a sus semejantes y tolerancia y aceptación de la diversidad; no estafes ni te aproveches indebidamente de los errores o adversidades de otros.

6. Ver por los demás

Sé atento, amable y compasivo; comparte, sé dadivoso, ayuda a los demás; ayuda a 
los necesitados y evita hacer daño a los demás.

7. Respeto a los demás

Demuestra respeto por la dignidad, la intimidad y el derecho a la autodeterminación de la gente; sé cortés, expedito y decente; da a los demás la información que necesitan para tomar decisiones informadas sobre sus propias vidas; no trates a los demás con aire condescendiente, no los avergüences ni los degrades.

8. Ciudadano responsable

Obedece las leyes; si una ley es injusta, protesta abiertamente; ejerce todos tus derechos y privilegios democráticos con responsabilidad participando (votando y expresando opiniones informadas), con conciencia social y servicio público; cuando estés en una posición de liderazgo o autoridad, respeta abiertamente y ennoblece los procesos democráticos de toma de decisiones, evita la reserva o el encubrimiento innecesario de información y asegúrate que los demás tengan la información que necesitan para hacer elecciones inteligentes y ejerzan sus derechos.

9. Búsqueda de la excelencia

Busca la excelencia en todo; en el cumplimiento de tus responsabilidades personales y profesionales; sé diligente, confiable, trabajador, y comprometido; realiza todas tus tareas lo mejor que puedas, crea y conserva un alto grado de competencia, infórmate y prepárate bien; no te conformes con la mediocridad; no "ganes a toda costa".

10. Responsabilidad

Sé responsable, acepta la responsabilidad de tus decisiones, de las consecuencias previsibles de tus acciones y omisiones y de poner el ejemplo a los demás. Los padres, maestros, empleadores, muchos profesionales y funcionarios públicos tienen obligación especial de enseñar con el ejemplo, de proteger y fomentar la integridad y reputación de sus familias, compañías, profesiones y del gobierno mismo; una persona sensible a la ética evita incluso la apariencia de deshonestidad, y emprende cualquier acción necesaria para corregir y evitar la conducta impropia en los demás.

\section{CARACTERÍSTICAS DE LA ÉTICA PRO- FESIONAL}

Tres son las características fundamentales de la ética profesional:

1. Es absoluta

Significa que su validez no se encuentra supeditada a normas extrañas, sino que por el contrario, es ella la que determina.

2. Es universal

Significa que obliga a todos los profesionales que se encuentran en igualdad de circunstancias.

3. Es inviolable

Significa que por su propia naturaleza, no pierde valor, aunque sea incumplida.

\section{LA ÉTICA Y EL CONTADOR PÚBLICO}

\section{La profesión contable es por excelencia una profesión autoregulada}

La vida del contador público que tiene ética es necesariamente distinta de los que no la tienen, su comportamiento, sus hábitos de vida, su forma de pensar, de valorar las situaciones, de decidir, son distintos porque se llevan a cabo a la luz de la ética y porque tienen distintos niveles de significado.

Los profesionales y particularmente los contadores públicos tenemos una amplia gama de principios y normas de ética. Por otra parte, 
dentro de la profesión de contador público, probablemente la auditoría es la especialidad que le presta más importancia a la ética, debido a que está presente en toda la extensión de su trabajo, sea en condición de auditor interno, auditor externo, auditor de organizaciones privadas o auditor gubernamental.

Pero, ¿qué se entiende por ética? o ¿cómo interpreta la ética, el profesional contable? Alvin A. Arens señala que la ética puede definirse en un sentido amplio como un conjunto de principios o valores morales; Ray $\mathrm{O}$. Whittingthon define la ética como el estudio del juicio moral y de las normas de conducta; y la International Federation of Accountants (IFAC) la define como una ciencia normativa cuyo objeto es el estudio de la bondad o maldad de los actos humanos, tanto en lo que respecta a sí mismos como en función de la sociedad.

$\mathrm{Y}$, ¿qué son los valores morales? Los valores morales son aquellas condiciones que perfeccionan al hombre en lo más alto de la escala de valores, puesto que tienen que ver con las causas finales de todos sus actos, son las razones más altas que los hacen trascender de todos sus actos infrahumanos e inframorales, le dan sentido a toda su existencia, su razón misma de vida y participación en lo absoluto.

\section{PRINCIPIOS Y NORMAS DE ÉTICA EN LA AUDITORÍA}

Muchas organizaciones profesionales y de auditoría han emitido principios y normas de ética, generalmente bajo la forma y denominación de Códigos de Ética, que son un conjunto de reglas de conducta que ha decidido adoptar la profesión organizada de contador público. Ante la sociedad, son reglas autónomas y ante los individuos que se agrupan en la institución profesional, constituyen reglas obligatorias en función del vínculo jurídico que los une. Debe entenderse sin embargo, que estos conjuntos normativos son guías mínimas de orientación o criterio, porque el accionar concreto del contador público o auditor en situaciones particulares, reside en los principios generales de los propios códigos y en los principios de la ciencia ética inscritos en el interior del hombre.

Los Códigos de Ética más importantes son los siguientes:

En el ámbito profesional:

1. Código de Ética Profesional de la IFAC

2. Código de Ética Profesional de AICPA (EE.UU.)

3. Código de Ética del Auditor Interno EE.UU. (CIA)

4. Código de Ética Profesional del Institute Canadian Accountants Ontario (Canadá)

5. Código de Ética del Instituto Mexicano de Contadores Públicos (México)

6. Código de Ética de la Federación de Colegios de Contadores Públicos del Perú y su junta de Decanos.

En el ámbito gubernamental:

7. Código de Ética del INTOSAI

8. Código de Ética del Auditor Gubernamental - Perú

A continuación, se presenta un resumen de cada uno de ellos: 


\section{Código de Ética Profesional de}

\section{International Federation of Accountants - IFAC}

(Federación Internacional de Contadores Públicos)

Sección 1: Objetividad

Parte A

Aplicable a todos los contadores públicos

Sección 2: Resolución de conflictos éticos

Sección 3: Competencia profesional

Sección 4: Confidencialidad

Sección 5: Práctica fiscal

Sección 6: Actividades a través de las fronteras

Sección 7: Publicidad

- Designaciones y premios

- Contadores públicos que buscan empleo o negocios profesionales

- El trabajo de subcontratación en busca de publicidad

- Directorios

- Libros, artículos, entrevistas, lecturas y apariciones en radio y televisión

- Cursos de entrenamiento, seminarios, etc.

- Panfletos y documentos que contienen información técnica

- Nombramiento en compañía

\section{Parte B}

\section{Aplicable a los profesionales en la práctica pública}

Sección 8: Independencia

- Participación financiera con o en los asuntos de clientes

- Nombramiento en compañía

- Provisión de otros servicios a clientes de auditoría

- Relaciones personales y familiares

- Honorarios

- Honorarios contingentes

- Bienes y servicios

- Propiedad del capital

- Socios anteriores

- Litigio o amenaza de litigio

Sección 9: Honorarios y comisiones

Sección 10: Actividades que son incompatibles con la práctica de la contaduría pública

Sección 11: Recursos del cliente

Sección 12: Relaciones con otros contadores profesionales en la práctica pública

- Aceptación de nuevos compromisos

- Sustitución de otro contador profesional en la práctica pública

Sección 13: Promoción y solicitud

- Publicidad de profesionales en la práctica pública en un ambiente no promocional

- Reclutamiento de personal

- Publicidad para beneficio del cliente

- Panfletos y directorios de firmas

- Papelería y placas

- Anuncios de periódicos

- Inclusión del nombre de un contador en la práctica profesional, en un documento publicado por un cliente. 


\author{
Código de Ética Profesional de \\ American Institute Certified Publics Accountants - AICPA (EE. UU.) \\ (Instituto Americano de Contadores Públicos Certificados)

\section{Sección I: Principios \\ Preámbulo}

La membrecia del Instituto Americano de Contadores Públicos Certificados es voluntaria. Al aceptar la membrecía, un contador público certificado asume la obligación de autodisciplina, que supera y trasciende los requisitos de las leyes y las regulaciones.

\title{
Artículo I: Responsabilidades
}

Al cumplir sus responsabilidades como profesionales, los miembros deben ejercer juicios morales y profesionales sensibles en todas sus actividades.

\section{Artículo II: El interés público}

Los miembros deben aceptar la obligación de actuar de modo que estén al servicio del interés público, honren la confianza del público y demuestren un compromiso con la profesión.

\section{Artículo III: Integridad}

Para mantener y ampliar la confianza del público, los miembros deben desempeñar todas las responsabilidades profesionales con el más alto sentido de integridad.

\section{Artículo IV: Objetividad e independencia}

El miembro debe mantener la objetividad y quedar libre de conflictos de interés en el cumplimiento de las responsabilidades profesionales. En el ejercicio público un miembro debe ser independiente, de hecho y en apariencia, al proporcionar auditorías y otros servicios de atestación.

\section{Artículo V: Debido cuidado profesional}

El miembro debe observar las normas éticas y técnicas de la profesión, buscar continuamente el mejoramiento de la competencia y calidad de los servicios, y cumplir la responsabilidad profesional haciendo uso de su mejor capacidad.

\section{Artículo VI: Alcance y naturaleza de los servicios}

En el ejercicio público el miembro debe observarse los principios del Código de Conducta Profesional al determinar el alcance y la naturaleza de los servicios que deben proporcionarse.

\section{Sección II: Reglas Aplicabilidad}

Los estatutos del Instituto Americano de Contadores Públicos Certificados exigen que los miembros se adhieran a las reglas del Código de Conducta Profesional. Los miembros deben estar preparados para justificar desviaciones de estas reglas.

\section{Regla 101: Independencia}

En el ejercicio público, un miembro debe ser independiente en el desempeño de los servicios profesionales, en la forma requerida por las normas promulgadas por los organismos designados por el Consejo.

\section{Regla 102: Integridad y objetividad}

En el desempeño de cualquier servicio profesional, un miembro debe mantener objetividad e integridad, debe estar libre de conflictos de interés y no debe tergiversar, intencionalmente, los hechos o subordinar un juicio al de otros.

\section{Regla 201: Normas generales}

Un miembro debe ajustarse a las siguientes normas y a las interpretaciones que de alli surjan por parte de los órganos designados por el Consejo: 
a. Competencia profesional. Emprender solamente aquellos servicios profesionales que el miembro o la firma del miembro puedan esperar terminar razonablemente con competencia profesional.

b. Debido cuidado profesional. Ejercer debido cuidado profesional en el desempeño de los servicios profesionales.

c. Planeación y supervisión. Planear y supervisar adecuadamente el desempeño de los servicios profesionales.

d. Información suficiente y pertinente. Obtener información suficiente y pertinente para ofrecer una base razonable para las conclusiones o recomendaciones con relación a los servicios profesionales prestados.

\section{Regla 202: Cumplimiento de las normas}

Un miembro que realiza servicios de auditoría, revisión, recopilación, consultoría gerencial, tributarios u otros servicios profesionales, debe cumplir las normas promulgadas por los órganos $u$ organizaciones nombrados por el Consejo.

\section{Regla 203: Principios de contabilidad}

Un miembro no debe 1) expresar una opinión o afirmar que los estados financieros $u$ otra información financiera de cualquier entidad están presentados de conformidad con los principios de contabilidad generalmente aceptados; ó 2) afirmar que no conoce modificaciones materiales que deban hacerse a esos estados o datos, con el fin de que éstos estén de conformidad con los principios de contabilidad generalmente aceptados, si esos estados o información contienen alguna desviación de un principio de contabilidad promulgado por los órganos o por el Consejo para establecer tales principios que tienen un efecto material sobre los estados o sobre la información tomada como un todo. Sin embargo, si los estados o la información contienen esa desviación y un miembro puede demostrar que debido a circunstancias poco usuales los estados financieros o la información serían de lo contrario malinterpretados, el miembro puede ajustarse a la regla describiendo la desviación, sus efectos aproximados, de ser práctico; y las razones por las cuales la conformidad con el principio daría como resultado una declaración engañosa.

\section{Regla 301: Información confidencial del cliente}

Un miembro en ejercicio público no deberá revelar información confidencial alguna del cliente, sin el consentimiento específico de éste.

\section{Regla 302: Honorarios condicionados}

Un miembro en ejercicio público no deberá:

1. Prestar mediante honorarios condicionados servicio profesional o recibir esa tarifa de un cliente para quien el miembro o la firma del miembro realiza:

a. Una auditoría o revisión de los estados financieros; 0

b. Una recopilación de unos estados financieros cuando el miembro espera, o podría esperar razonablemente, que un tercero utilizará los estados financieros y que el informe de recopilación del miembro ro revela una falta de independencia; o

c. Un examen anticipado de información financiera.

2. Preparar una declaración original o una corrección del impuesto sobre la renta o un reclamo de devolución de impuestos por unos honorarios condicionados para cualquier cliente.

\section{Regla 501: Actos deshonrosos}

Un miembro no deberá cometer un acto que desacredite la profesión.

\section{Regla 502: Publicidad y otras formas de oferta de servicios}

Un miembro en ejercicio público no debe buscar clientes mediante publicidad u otras formas de oferta de servicios en una forma que sea falsa, aparente o engañosa. Está prohibida la oferta de servicios mediante el uso de la coacción, las contrataciones muy ambiciosas o una conducta de hostilidad.

\section{Regla 503: Comisiones y honorarios por referencias}

1. Comisiones prohibidas. Un miembro èn ejercicio público no deberá recomendar o referir a un cliente cualquier producto o servicio, a cambio de una comisión, o recomendar o referir cualquier producto o servicio que deba ser suministrado por un cliente, por una comisión, o recibir una comisión, cuando el miembro o la firma del miembro también realiza para ese cliente:

a. Una auditoría o revisión de sus estados financieros.

b. Una recopilación de estados financieros cuando el miembro espera, o podría esperar razonablemen- 
te, que un tercero utilizará los estados financieros, y que el informe de recopilación del miembro no revela una falta de independencia.

c. Un examen de información financiera anticipado. Esta prohibición se aplica durante el período en el cual el miembro está comprometido a realizar cualquiera de los servicios enumerados arriba y durante el período cubierto por los estados financieros históricos involucrados en esos servicios enumerados.

2. Revelación de comisiones permitidas. Un miembro en ejercicio público al que no se le ha prohibido mediante esta regla la prestación de servicios o el recibir una comisión, y que se le ha pagado o espera recibir una comisión, deberá revelar ese hecho a cualquier persona o entidad a la cual el miembro recomienda o refiere un producto o servicio con el cual se relaciona la comisión.

3. Comisiones por referencias. Cualquier miembro que acepta honorarios por referencia por recomendar o referir cualquier servicio de un CPA a cualquier persona o entidad o que paga una comisión por referencia para obtener un cliente, debe revelar al cliente esa aceptación o pago.

\title{
Regla 504: (Suprimida)
}

\section{Regla 505: Forma y nombre de la organización}

Un miembro puede ejercer la contaduría pública en una forma de organización permitida por la ley o la regulación estatal, cuyas características se ajustan a las resoluciones del concejo municipal.

Un miembro no debe ejercer la contaduría pública bajo el nombre de una firma que sea engañoso. Los nombres de uno o más dueños en el pasado pueden ser incluidos en el nombre de la firma de una organización sucesora. Además, un propietario que sobrevive a la muerte o retiro de todos los demás propietarios puede continuar ejerciendo bajo un nombre que incluye los nombres de dueños anteriores hasta dos años después de convertirse en profesional individual.

Una firma no puede nombrarse a sí misma "Miembro del Instituto Americano de Contadores Públicos Certificados", a menos que todos sus dueños sean miembros del Instituto.

\author{
Código de Ética del \\ Certified Internal Auditors - CIA (EE. UU.) \\ (Instituto de Auditores Internos)
}

\section{Propósito}

Una marca distintiva de una profesión es la aceptación por parte de sus miembros de asumir responsabilidad frente a los intereses de aquéllos que sirven. Los miembros del instituto de los miembros internos (miembros) y los auditores internos certificados (Certified Internal Auditors - CIA) deben mantener altas normas de conducta, con el fin de realizar efectivamente esta responsabilidad. El Instituto de Auditores Internos (instituto) adopta este código de ética para los miembros y los $\mathrm{ClA}$.

\section{Normas de conducta}

I. Los miembros y los CIA deberán proceder con honestidad, objetividad y diligencia en el desempeño de sus deberes y responsabilidades.

II. Los miembros y los CIA deberán mostrar lealtad en todos los asuntos relacionados con los problemas de su organización o con quienquiera al que ellos estén prestando un servicio. Sin embargo, los miembros y los CIA no participarán adrede en ninguna actividad ilegal o inapropiada.

III. Los miembros y los CIA no deberán comprometerse adrede en actos o actividades que desacreditan la profesión de auditoría interna o su organización.

IV. Los miembros y los CIA evitarán participar en cualquier actividad que pueda estar en conflicto con el interés de su organización o que pueda perjudicar su capacidad de realizar objetivamente sus deberes y responsabilidades.

V. Los miembros y los CIA no deberán aceptar nada de valor de un empleado, cliente habitual u ocasional, proveedor o asociado de negocios de su organización, que debilite o se suponga que debilita su juicio profesional.

VI. Los miembros y los CIA deberán aceptar solamente aquellos servicios que puedan terminar razonablemente con competencia profesional.

VII. Los miembros y los CIA deberán adoptar medios apropiados para ajustarse a las Normas para la Práctica Profesional de Auditoría Interna. 
VIII. Los miembros y los CIA deben ser prudentes en el uso de la información adquirida en el curso de sus deberes. No utilizarán información confidencial para obtener alguna ganancia personal, ni en forma alguna que fuera contraria a la ley o en detrimento del bienestar de su organización.

IX. Los miembros y los $\mathrm{ClA}$, al presentar el informe sobre los resultados de su trabajo, deberán revelar todos los hechos materiales conocidos por ellos que, de no ser revelados, podrían distorsionar los informes de operaciones bajo revisión u ocultar prácticas ilegales.

$X$. Los miembros y los CIA deberán buscar continuamente el mejoramiento en su idoneidad y en la efectividad y calidad de su servicio.

$\mathrm{XI}$. Los miembros y los CIA, en el ejercicio de su profesión, deberán ser conscientes de su obligación de mantener los altos niveles de competencia, moralidad y dignidad promulgados por el Instituto. Los miembros deberán ajustarse a los Estatutos y defender los objetivos del Instituto.

\author{
Código de Ética Profesional \\ Institute Canadian Accountants Ontario \\ (Instituto de Contadores Públicos de Ontario, Canadá)
}

\author{
Reglas de conducta profesional \\ 100 General \\ 101 Obediencia a los estatutos, regulaciones y reglas \\ 102 Condenas de ofensas criminales o similares \\ 103 Solicitudes falsas o engañosas \\ 104 Requerimiento para contestar por escrito
}

200 Normas de conducta que afectan al interés público

201 Mantenimiento de la reputación de la profesión

202 Integridad y cuidado del deber

203.1 Competencia profesional

203.2 Cooperación con las inspecciones de la práctica y la investigación de la conducta

204.1 Objetividad: compromisos de auditoría

204.2 Objetividad: compromisos de revisión

204.3 Objetividad: compromisos de insolvencia

204.4 Revelación de conflictos

205 Documentos falsos o engañosos y presentaciones orales

206 Obediencia a las normas profesionales

207 Información a los clientes y asociados de posibles conflictos de interés

208 Beneficios no autorizados

209 Uso impropio de información confidencial

210 Confidencialidad de la información

211 Deber de reportar la violación a las reglas de conducta profesional

212.1 Manejo de fondos encomendados y otras propiedades

212.2 Manejo de la propiedad de otros

213 Actividades ilegales

214 Cotización de honorarios

215 Honorarios contingentes y servicios sin honorarios

216 Pago o recepción de comisiones

217.1 Publicidad general

217.2 Garantías

218 Retención de documentación y papeles de trabajo

300 Relaciones con miembros compañeros y no miembros comprometidos con la práctica pública 301.1 Obtención o atracción de clientes

301.2 Solicitudes

302 Comunicación con el predecesor

303 Cooperación con el sucesor

304 Compromisos conjuntos

305 Comunicación de compromisos especiales a los interesados

306.1 Responsabilidades al aceptar compromisos

306.2 Responsabilidades con los compromisos requeridos 
400 Organización y conducta en la práctica profesional

401 La práctica engañosa de nombres prohibidos

402 Práctica de un solo propietario

403 Nombres de las firmas

404.1 Uso de nombres descriptivos

404.2 Operación de las oficinas de los miembros

404.3 Interés del propietario con los no miembros

405 Asociación con firmas

406 Responsabilidad del miembro hacia no miembros

407 Oficina de representación

408 Práctica de contabilidad pública en forma corporativa

409-419 (Reservado para el futuro)

420 Práctica de funciones relacionadas

421 La funciones relacionadas deben adherirse a las reglas de conducta profesional

\section{Código de Étíca Profesional del \\ Instituto Mexicano de Contadores Públicos}

\section{Postulados}

\section{Alcance del Código}

\section{Postulado 1}

Aplicación universa! del código. Este código de Ética Profesional es aplicable a todo contador público por hecho de serlo, sin importar la índole de su actividad o especialidad que cultive tanto en el ejercicio independiente o cuando actúe como funcionario o empleado de instituciones públicas o privadas. Abarca también a los contadores públicos que además ejerzan otra profesión.

\section{Responsabilidad hacia la sociedad}

\section{Postulado II}

Independencia de criterio. Al expresar cualquier juicio profesional el contador público acepta la obligación de sostener un criterio libre e imparcial.

\section{Postulado III}

Calidad profesional de los trabajos. En la prestación de cualquier servicio se espera del contador público un verdadero trabajo profesional, por lo que siempre tendrá presente las disposicionés normativas de la profesión que sean aplicables al trabajo específico que esté desempeñando. Actuará así mismo con la intención, el cuidacio y la diligencia de una persona responsable.

\section{Postulado IV}

Preparación y calidad del profesional. Como requisito para que el contador público acepte prestar sus servicios, deberá tener el entrenamiento técnico y la capacidad necesaria para realizar las actividades profesionales satisfactoriamente.

\section{Postulado V}

Responsabilidad personal. El contador público siempre aceptará una responsabilidad personal por los trabajos llevados a cabo por él o realizados bajo su dirección.

\section{Responsabilidades hacia quien patrocina los servicios}

\section{Postulado VI}

Secreto profesional. El contador público tiene la obligación de guardar el secreto profesional y de no revelar por ningún motivo los hechos, datos o circunstancias de que tenga conocimiento en el ejercicio de su profesión, a menos que lo autoricen los interesados, excepto por los informes que establezcan las leyes respectivas. 


\section{Postulado VII}

Obligación de rechazar tareas que no cumplan con la moral. Faltará al honor y dignidad profesional todo contador público que directa o indirectamente intervenga en arreglos o asuntos que no cumplan con la moral.

\section{Postulado VIII}

Lealtad hacia el patrocinador de los servicios. El contador público se abstendrá de aprovecharse de situaciones que puedan perjudicar a quien a contratado sus servicios.

\section{Postulado IX}

Retribución económica. Por los servicios que presta, el contador público se hace acreedor a una retribución económica.

\section{Responsabilidad hacia la profesión}

\section{Postulado X}

Respeto a los colegas y a la profesión. Todo contador público cuidará sus relaciones con sus colaboradores, con sus colegas y con las instituciones que los agrupan buscando que nunca se menoscabe la dignidad de la profesión sino que se enaltezca, actuando con espíritu de grupo.

\section{Postulado XI}

Dignificación de la imagen profesional a base de calidad. Para hacer llegar a la sociedad en general y a los usuarios de sus servicios una imagen positiva y de prestigio profesional, el contador público se valdrá fundamentalmente de su calidad profesional y personal, apoyándose en la promoción institucional y cuando lo considere conducente, para aquellos servicios diferentes a los de dictaminación, podrá comunicar y difundir sus propias capacidades sin demeritar a sus colegas o a la profesión en general.

\section{Postulado XII}

Difusión y enseñanza de conocimientos técnicos. Todo contador público que de alguna manera transmita sus conocimientos, tendrá como objeto mantener las más altas normas profesionales y de conducta y contribuir al desarrollo y difusión de los conocimientos propios de la profesión.

1. Normas generales

2. Del contador público como profesional independiente

1. general

2. del contador público como auditor externo

3. Del contador publico en los sectores público y privado

4. Del contador público en la docencia

5. Sanciones

\section{Código de Ética Profesional de la}

Federación de Colegios de Contadores Públicos del Perú y su Junta de Decanos

(Aprobado por el XVI Congreso Nacional de Contadores Públicos del Perú - Tumbes, octubre de 1998)

\section{TEXTO ÚNICO ORDENADO}

\section{Capítulo I \\ Alcance e interpretación}

Art. $1^{\circ}$. Las normas contenidas en el presente Código de Ética Profesional, son aplicables a los miembros de los Colegios de Contadores Públicos del país en el ejercicio de la profesión, tanto en forma individual como asociada.

Art. $2^{\circ}$. El Contador Público está obligado a adecuar su conducta profesional de acuerdo con normas preceptuadas en el presente Código.

Art. $3^{\circ}$. El presente Código rige la conducta del Contador Público tanto en el ejercicio independiente 
como dependiente de la profesión contable, siéndole aplicable cualquiera que sea la forma que adopte en su actividad profesional o la naturaleza de la retribución que perciba.

Este Código, asimismo, norma la conducta profesional del Contador Público con sus colegas de profesión.

Art. $4^{\circ}$. Los Contadores Públicos que, además del ejercicio de la profesión, ejerzan otras profesiones, deberán acatar las normas de conducta que señala este Códligo para el desarrollo de la actividad de Contador Público, independientemente de aquéllas que rijan el ejercicio de las otras profesiones.

Art. $5^{\circ}$. Los Colegios de Contadores Públicos constituirán un Comité de Ética Profesional el cuál informará al Consejo Directivo de la infracción o no del Código de Ética Profesional. El Consejo Directivo trasladará el informe a la primera instancia del Tribunal de Honor para que aplique o no la sanción que corresponda. El Tribunal de Honor resolverá los casos de dudas acerca de la interpretación del presente Código.

Art. $6^{\circ}$. Corresponderá al Consejo Directivo divulgar y velar por el cumplimiento de la sanción que sólo podrá ser apelada ante el propio Tribunal de Honor en instancia final. Para dicho propósito deberá conformarse un Tribunal de Honor Adhoc con Past Decanos o Past Vice Decanos que no integren el Tribunal de Honor permanente. Dicho Tribunal se pronunciará en fallo inapelable sobre la procedencia o no de la sanción prevista en el Código de Ética Profesional.

\section{Capítulo II \\ Normas generales de ética}

Art. $7^{\circ}$. En el ejercicio profesional, el Contador Público actuará con probidad y buena fe, manteniendo el honor, dignidad y capacidad profesional, observando las reglas de ética más elevadas en todos sus actos.

Art. $8^{\circ}$. Ningún Contador Público podrá tomar ni apoyar iniciativas para modificar el estatus del Colegio ni podrá hacer declaraciones públicas en contra de la Institución.

Art. $9^{\circ}$. El Contador Público que sea miembro de otras Instituciones se abstendrá de intervenir directa e indirectamente, en actos que sean lesivos a la profesión de Contador Público.

Art. $10^{\circ}$. El Contador Público no debe desarrollar actividades que resulten incompatibles con el ejercicio de la profesión. El Comité de Ética informará al Consejo Directivo acerca de la compatibilidad o incompatibilidad a que se refiere esta norma. El Tribunal de Honor a pedido de parte o de oficio se pronunciará en instancia definitiva sobre la incompatibilidad.

Art. $11^{\circ}$. Cuando un Contador Público Colegiado acepte un cargo incompatible con el ejercicio independiente de la profesión, deberá dejar en suspenso sus actividades profesionales en tanto dure la incompatibilidad.

\section{Responsabilidad profesional}

Art. $12^{\circ}$. El Contador Público que actúe en función independiente como dependiente, asumirá responsabilidad profesional en relación a sus informes, dictámenes, declaraciones juradas, etc., refrendados con su firma.

Art. $13^{\circ}$. Ningún Contador Público, sea cual fuere la causa, podrá retener libros ni documentación contable de sus clientes, por tratarse de una apropiación indebida. Cualquier diferendo deberá dilucidarse en la vía que corresponda.

\section{Secreto profesional}

Art. $14^{\circ}$. El Contador Público tiene obligación de guardar el secreto profesional y de no revelar por ningún motivo los hechos, datos o circunstancias de los que tenga conocimiento en el ejercicio de su profesión, excepto por las informaciones que obligan las disposiciones legales.

Art. $15^{\circ}$. Ningún Contador Público podrá beneficiarse haciendo uso de la información que obtenga en el ejercicio de la profesión, ni podrá comunicar dicha información a otras personas con intenciones que aprovechen en igual sentido.

Art. $16^{\circ}$. El Contador Público podrá consultar o intercambiar impresiones con otros colegas en cuestio- 
nes de criterio o de doctrina, pero nunca deberá proporcionar datos que identifiquen a las personas o negocios de que se trate, a menos que sea con consentimiento de los interesados.

\section{Independencia de criterio}

Art. $17^{\circ}$. El Contador en el desempeño de su función, cualquiera que sea su campo de actuación, debe mantener independencia de criterio, ofreciendo el mayor grado de objetividad e imparcialidad. Sus actuaciones, informes y dictámenes deben basarse en hechos debidamente comprobables en aplicación de los principios de contabilidad (NIC) y de auditoría (NIA) y las técnicas contables aprobadas por la profesión en los Congresos Nacionales e Internacionales.

Art. $18^{\circ}$. El Contador Público debe tener presente que su actuación profesional conduce a tomar decisiones que repercuten hacia terceros, por lo que al emitir sus opiniones deberá hacerlos con independencia de criterio.

Art. $19^{\circ}$. Se considera que no hay independencia ni imparcialidad para expresar una opinión acerca del asunto que se somete a su consideración en función de auditor cuando el Contador Público sea pariente consanguíneo en línea recta sin limitación de grado, colateral dentro del cuarto grado, y dentro del segundo grado del propietario o socio principal de la empresa o de algún director, administrador, gerente o funcionario que tenga intervención de importancia en la administración del asunto examinado.

Art. $20^{\circ}$. Tampoco se considera que hay independencia cuando el Contador Público, actuando como Auditor Independiente, esté vinculado económica o administrativamente con la empresa o filiales y con sus directivos; o cuando es propietario de la empresa o tenga vinculación con ella en grado tal, que pueda afectar su libertad de criterio.

Art. $21^{\circ}$. La labor del Contador Público como Perito Contable Judicial debe ser objetiva e impersonal. El interés Supremo de la Justicia debe presidir su labor y sus razonamientos.

\section{Relación entre colegas}

Art. $22^{\circ}$. El Contador Público podrá asociarse para el ejercicio profesional, de acuerdo a dispositivos legales vigentes y los que rijan para nuestra profesión.

La Sociedad o estudio deberá darse a conocer con el nombre de uno o más de sus miembros, pudiendo añadir la calificación de Contadores Públicos.

Ningún Contador Público podrá ser socio de más de una Sociedad de Contadores Públicos.

Art. $23^{\circ}$. El Contador Público deberá abstenerse en forma absoluta de formular opiniones, comentarios o juicios negativos sobre la intervención profesional o idoneidad de otro colega. Cualquier opinión sobre el particular deberá ser expresada ante las instancias pertinentes de su Colegio Profesional.

Art. $24^{\circ}$. Los nombres de los socios retirados o fallecidos no podrán conservarse ni incluirse en la denominación o razón social de la sociedad a que hayan pertenecido.

Art. $25^{\circ}$. En las sociedades de profesionales sólo podrán suscribir o refrendar informes y estados financieros quienes poseen título de Contador Público otorgado por una Universidad Peruana o revalidado en ella y debidamente colegiados e inscrita la sociedad en el registro correspondiente.

\section{Capítulo III \\ Campo de la profesión}

Art. $26^{\circ}$. El Contador Público puede ejercer su actividad:

a) En función dependiente.

b) En función independiente.

\section{El contador público en función de profesional dependiente}

Art. $27^{\circ}$. El Contador Público como profesional en función dependiente deberá fomentar permanentemente la conciencia tributaria, y asimismo mantenerse actualizado en los conocimientos inherentes a las áreas de su servicio profesional. 
Art. $\mathbf{2 8}^{\circ}$. El Contador Público que desempeñe en alguna institución el cargo de docente tendrá comc objetivo mantener y enseñar las más altas normas profesionales y de conducta, y contribuir al desarrollo y difusión de los conocimientos propios de la profesión.

En tal virtud, deberá impartir una enseñanza técnica útil y orientar al alumno para que en su futuro ejercicio profesional actúe con estricta observancia a las reglas de ética que le impone la profesión.

Art. $29^{\circ}$. El Contador Público que ejerza independientemente no expresará su opinión profesional sobre los estados financieros o sobre cualquier otra información financiera complementaria, si el examen de dichos estados o información no ha sido practicado por él, o bajo su supervisión.

Art. $30^{\circ}$. El Contador Público que ejerza independientemente no expresará su opinión profesional sobre los estados financieros o sobre cualquier otra información financiera complementaria, si el examen de dichos estados o información no ha sido practicado por él, o bajo su supervisión.

Art. $31^{\circ}$. El dictamen, informe u opinión del Contador Público debe ser redactado de tal manera que exprese claramente su opinión profesional sobre el particular, en concordancia con las normas y procedimientos aprobados por la profesión contable.

Art. $32^{\circ}$. El Contador Público no permitirá que se presenten estados, documentos o información en papel con su membrete cuando no han sido examinados por él.

Art. $33^{\circ}$. El Contador Público que fuera solicitado para dictaminar estados financieros a una misma fecha en que hayan sido examinados por otro u otros Contadores Públicos, evitará dicho encargo, salvo casos de exámenes especiales o de fuerza mayor, debidamente justificados con conocimiento al colegio de Contadores Públicos correspondiente.

Art. $34^{\circ}$. Ningún Contador Público que ejerza independientemente, permitirá actuar en su nombre a persona que no sea su representante debidamente acreditado o empleado bajo su autoridad.

Art. $35^{\circ}$. El Contador Público no podrá realizar ningún tipo de trabajo de auditoría o peritaje contable judicial en las empresas en que haya trabajado como Contador, sino después de dos años. Mientras dure su actuación como Contador no podrá como auditor.

Art. $36^{\circ}$. No es posible efectuar trabajos de auditoria o peritaje contable judicial en las empresas en donde se actúa como Contadores a través de empresas de contabilidad Outsourcing vinculadas con los auditores o por personas que tengan dependencia con los auditores o peritos contables judiciales.

Art. $37^{\circ}$. En los servicios de contabilidad, consultoría y peritajes independientes prestados por personas jurídicas, asume la responsabilidad el profesional contable que firme o suscriba los estados financieros, declaraciones juradas de impuestos y contribuciones e informes en general.

Art. $38^{\circ}$. El informe o dictamen del Contador Público en su calidad de perito, consultor o auditor independiente deberá de estar debidamente sustentado con papeles de trabajo o correspondencia en cumplimiento de los NIAS, o de las técnicas contables aprobadas por la profesión en Congresos Nacionales o internacionales.

\section{Capítulo IV \\ Retribución económica}

Art. $39^{\circ}$. El Contador Público el tiempo de contratar el compromiso de prestar sus servicios debe determinar con sus usuarios el monto de sus honorarios, tomando como referencia, así como la responsabilidad que asume, la importancia de la empresa y otros factores, de manera que, por exceso o por defecto, dicha base no resulte lesiva a la dignidad profesional o sea contraria a toda regla de justa compensación. Consecuentemente evitará toda controversia con sus clientes acerca de honorarios.

Art. $40^{\circ}$. El Contador Público no ofrecerá o prestará servicios profesionales a cambio de honorarios que dependan de la eventualidad de las averiguaciones o de los resultados de tales servicios.

Se excluye de esta limitación los honorarios de consultoría originados en ideas no provenientes de la actuación como contadores, auditores y peritos judiciales. 


\section{Capítulo V \\ Anuncio de servicios profesionales}

Art. $41^{\circ}$. El Contador Público individual o asociadamente podrá ofrecer sus servicios en forma seria y mesurada, bajo las siguientes modalidades de publicidad:

a) En anuncios en periódicos o revistas.

b) El Contador Público que ejerza docencia universitaria no podrá efectuar anuncios de servicios profesionales para la enseñanza y el que no ejerza, no podrá asociar el título profesional en anuncios para la enseñanza regular en Institutos, Escuelas, Academias, Cenecapes, ONG, etc.

Art. $42^{\circ}$. La identificación del Contador o de la firma profesional debe limitarse a anunciar el nombre individual o razón social de la firma, el título profesional, dirección y su representación, asociación o agrupación si la hubiere.

Art. $43^{\circ}$. Está prohibida la publicidad escrita o verbal utilizando nombre, siglas, o letras en la misma conformación de la razón social registrada en el Colegio de Contadores Públicos.

Art. $44^{\circ}$. Se atenta contra la ética profesional en la oferta de servicios o solicitudes de trabajo que efectúe el Contador Público, individual o asociadamente, en los siguientes casos:

a) En el envio de cartas o currículas a empresas ofreciendo sus servicios, sin que ellos le fueran requeridos.

b) En la distribución de volantes.

c) En la contratación de comisionistas o corredores.

d) En anuncios a través de medios de comunicación.

Art. $45^{\circ}$. No se considera como publicidad, la divulgación de obras, folletos, boletines, trabajos técnicos o estudios de investigación, de práctica profesional, de orientación o de información, elaborados por Contadores Públicos, que representen temas de interés general o de la profesión en particular.

\section{Capitulo VI \\ Infracciones al Código de Ética}

Art. $46^{\circ}$. La inobservancia de los preceptuado en el presente Código de Ética Profesional constituye infracción, la cual será sancionada de acuerdo con la gravedad de la misma, sin perjuicio de lo expresamente tipificado como infracción en el presente capítulo.

Art. $47^{\circ}$. El Contador Público, cualquiera que fuera el campo en el que actúa, es responsable de sus actos y considerado causante de un acto de descrédito para la profesión, si al expresar su opinión sobre el asunto que haya examinado o sobre cualquier información de carácter profesional.

a) Encubra un hecho importante a sabiendas que es necesario manifestarlo para que su opinión no induzca a conclusiones erradas.

b) Deje de manifestar expresamente cualquier dato importante que deba aparecer en los estados financieros en sus informes y del cual tenga conocimiento.

c) Incurra en negligencia al emitir el informe correspondiente a su trabajo, sin haber observado las normas, técnicas y procedimientos de contabilidad o auditoría exigidos en las circunstancias, para respaldar su trabajo profesional sobre el asunto encomendado o expresa su opinión cuando las limitaciones al alcance de su trabajo son de tal naturaleza que le impidan emitir tal opinión.

d) No informe, siendo de su conocimiento, sobre cualquier desviación substancial de los principios de contabilidad generalmente aceptados o de cualquier omisión importante aplicable en las circunstan. cias al caso que le ocupa.

e) Aconseje falsear los estados financieros y cualquier otra información de su cliente, o de las dependencia en donde presente sus servicios.

En suma, las opiniones, informes, dictámenes y documentos que presente el contador público deberán contener la expresión de su juicio fundado, sin ocultar o desvirtuar los hechos de manera que puedan inducir a error.

Art. $48^{\circ}$. Comete infracción grave y contraria a la dignidad profesional, el Contador Público que directa o indirectamente interviene en arreglos indebidos con sus clientes, oficinas públicas o cualquier otro organismo para obtener un trabajo o aceptar o conceder subrepticia o claramente, comisiones, corretajes o recompensas. 
Art. $49^{\circ}$. Comete infracción el Contador Público, que se vale de la función que desempeña para consegurdirecta $o$ indirectamente beneficios que no sean producto de su labor profesional.

Art. $50^{\circ}$. También comete infracción el Contador Público que demore injustificadamente la emisión y entrega de un informe o dictamen.

Art. $51^{\circ}$. Comete infracción el Contador Público, que edite y publique textos utilizando ejemplos o expresiones literales contenidas en publicaciones realizadas por profesionales del gremio o de otros profesionales liberales.

\section{Sanciones}

Art. $52^{\circ}$. El Contador Público que infrinja este Código será sancionado por el Colegio de Contadores Públicos de la respectiva Orden.

Art. $53^{\circ}$. Para la imposición de sanciones se tomará en cuenta la gravedad de la infracción cometida, evaluando dicha gravedad de acuerdo con la trascendencia que la falta tenga para el prestigio y estabilidad de la profesión de Contador Público.

Art. $54^{\circ}$. Según la gravedad de la falta, la sanción podrá consistir en:

a) Amonestación.

b) Suspensión temporal en el ejercicio de la profesión entre uno y veinticuatro meses.

c) Cancelación definitiva de la Matrícula en el Registro del Colegio.

Art. $55^{\circ}$. Los organismos encargados del cumplimiento de las normas del presente Código son:

a) El Comité de Ética Profesional.

b) El Consejo Directivo del Colegio.

c) El Tribunal de Honor.

Art. $56^{\circ}$. El procedimiento de los organismos citados para aplicar las sanciones, es el siguiente:

a) De carácter informativo.

El Comité de Ética Profesional, a requerimiento del Consejo Directivo.

b) De carácter resolutivo y apelativo.

El Tribunal de Honor.

c) De carácter ejecutivo

El Consejo Directivo.

Código de Ética para los Auditores del Sector Público de International Organization of Supreme Audit Institutions - INTOSAI

(Organización Internacional de Entidades Fiscalizadoras Superiores)

\section{Capitulo I: Introducción}

\section{Noción, antecedentes y propósito del Código de Ética}

1. La INTOSAI ha considerado que es esencial instaurar un Código de Ética Internacional para los auditores pertenecientes al sector público.

2. Un Código de Ética constituye una exposición que abarque los valores y principios que guían la labor cotidiana a los auditores. La independencia, las facultades y las responsabilidades del auditor en el sector público plantean elevadas exigencias éticas a las Entidades Fiscalizadoras Superiores (EFS) y al personal que emplean o contratan para la labor de auditoría. El código deontológico de los auditores pertenecientes al sector público debe tener en cuenta tanto las exigencias éticas de los funcionarios públicos en general como las exigencias específicas de los auditores en particular, incluidas las obligaciones profesionales de éstos.

3. Tomando como fundamento la Declaración de Lima de Directrices sobre Preceptos de la Auditoría (*) el Código de Ética de la INTOSAI deberá constituir un complemento necesario que fortalezca aún más las Normas de Auditoría de la INTOSAI emitidas en junio de 1992 por la Comisión de Normas de Auditoría de la INTOSAI.

(*) Correspondiente al IX Congreso de la INTOSAI, celebrado en Lima. Puede solicitarse a la Secretaría General de la INTOSAI, en Austria. 
4. El Código de Ética de la INTOSAl está dirigido al auditor individual, al director de las EFS, a los responsables ejecutivos y a todas las personas que trabajen al servicio de la EFS o en representación de ésta y que intervengan en la labor de auditoria. Sin embargo, no hay que considerar que el Código deba influir sobre la estructura organizativa de la EFS.

Debido a las diferencias nacionales de cultura, idioma y sistemas jurídicos y sociales, es responsabilidad de cada EFS la elaboración de un Código de Ética propio que se ajuste de manera óptima a su propio entorno. Conviene que estos Códigos de Ética nacionales especifiquen con claridad los conceptos éticos. El Código de Ética de la INTOSAI se propone servir de fundamento a los Códigos de Ética nacionales. Cada EFS tiene que garantizar que todos sus auditores estén familiarizados con los valores y principios que figuran en el Código de Ética nacional y actúen de acuerdo con ellos.

5. La conducta de los auditores deben ser irreprochable en todos los momentos y todas las circunstancias. Cualquier deficiencia en su conducta profesional o cualquier conducta inadecuada en su vida personal perjudica la imagen de integridad de los auditores, la EFS que representan la calidad y la validez de su labor de auditoría, puede plantear dudas acerca de la fiabilidad y la competencia profesional de la propia EFS. La adopción y la aplicación de un código de ética para los auditores del sector público promueven la confianza en los auditores y en su labor.

6. Tiene una importancia fundamental que la EFS suscite credibilidad y confianza. El auditor logra tal cosa mediante la adopción y la aplicación de las exigencias éticas de las nociones encarnadas en los siguientes conceptos claves: integridad, independencia y objetividad, confidencialidad y competencia profesional.

\section{Seguridad, confianza y credibilidad}

7. El poder legislativo y/o ejecutivo, el público en general y las entidades fiscalizadas tienen derecho a esperar que la conducta y el enfoque de la EFS sean irreprochables, no susciten sospechas y sean dignos de respeto y confianza.

8. Los auditores deben conducirse de un modo que promueva la cooperación y las buenas relaciones entre los auditores y dentro de la profesión. El apoyo de la profesión por parte de sus miembros y su cooperación recíproca constituyen elementos esenciales de la profesionalidad. Por consiguiente, tanto a los auditores como al público en general les interesa que el auditor trate a sus colegas auditores de una forma justa y equilibrada.

= El poder legislativo y/o ejecutivo, el público en general y las entidades fiscalizadas deberán tener una plena garantía de la justicia y la imparcialidad de toda la labor de la EFS. Por consiguiente, es esencial que exista un Código de Ética nacional o un documento semejante que rija la presentación de servicios.

0 . En todos los sectores de la sociedad existe la necesidad de credibilidad. Por consiguiente, resulta esencial que terceras personas expertas en la materia consideren que los informes y dictámenes de la EFS son minuciosamente precisos y fiables.

-1. Toda la labor realizada por la EFS debe contrastarse mediante la inspección realizada por el poder legislativo y/o ejecutivo, la evaluación pública acerca de su corrección, y el examen comparativo con un Código de Etica nacional.

\section{Capítulo II: Integridad}

"2. La integridad constituye el valor central de un Código de Ética. Los auditores están obligados a cumplir normas elevadas de conducta (por ejemplo, honradez e imparcialidad) durante su trabajo y en sus relaciones con el personal de las entidades fiscalizadas. Para preservar la confianza de la sociedad, la conducta de los auditores deben ser irreprochables y estar por encima de toda sospecha.

-3. La integridad puede medirse en función de lo que es correcto y justo. La integridad exige que los auditores se ajusten tanto a la forma como al espíritu de las normas de auditoría y de ética. La ntegridad también exige que los auditores se ajusten a los principios de objetividad e independencia, mantengan normas irreprochables de conducta profesional, tomen decisiones acordes con el interés público, y apliquen un criterio de honradez absoluta en la realización de su trabajo y el empleo de los recursos de la EFS.

$\because$ Para los auditores es indispensable la independencia con respecto a la entidad fiscalizada y otros grupos de intereses externos. Esto implica que los auditores actúen de un modo que aumente su ndependencia, o que no la disminuya por ningún concepto.

Los auditores no sólo deben esforzarse por ser independientes de las entidades fiscalizadas y de otros grupos interesados, sino también deben ser objetivos al tratar las cuestiones o los temas someridos a revisión. 
16. Es esencial que los auditores no sólo sean independientes e imparciales de hecho, sino que tambier lo parezcan.

17. En todas las cuestiones relacionadas con la labor de auditoría, la independencia de los auditores $n$ : debe verse afectada por intereses personales o externos. Por ejemplo, la independencia podr a verse afectada por las presiones o los influjos externos sobre los auditores; por los perjuicios de Ic 5 auditores acerca de las personas, las entidades fiscalizadas, los proyectos o los programas; po* haber trabajado recientemente en la entidad fiscalizada; o por relaciones personales o financieras que provoquen conflictos de lealtades o de intereses. Los auditores están obligados a no intervenır en ningún asunto en el cual tengan algún interés personal.

18. Se requiere objetividad e imparcialidad en toda la labor efectuada por los auditores, y en particular en sus informes, que deberán ser exactos y objetivos. Las conclusiones de los dictámenes e informes, por consiguiente, deben basarse exclusivamente en las pruebas obtenidas y unificadas de acuerdo con las normas de auditoría de la EFS.

19. Los auditores deberán utilizar la información aportada por la entidad fiscalizada y por terceros. Esta información deberá tenerse en cuenta de modo imparcial en los dictámenes expresados por los auditores: El auditor también deberá recoger información acerca de los enfoques de la entidad fiscalizada y de terceros. Sin embargo, estos enfoques no deberán condicionar las conclusiones propias de los auditores.

\section{Neutralidad política}

20. Es importante mantener la neutralidad -tanto la real como la percibida- de la EFS. Por lo tanto, es importante que los auditores conserven su independencia con respecto a las influencias políticas para desempeñar con imparcialidad sus responsabilidades de fiscalización. Esto es relevante para los auditores porque las EFS trabajan en estrecho contacto con los órganos legislativos, el poder ejecutivo u otros órganos de la Administración facultados por la ley para tomar en consideración los informes de las EFS.

21. Es importante que, cuando los auditores se dediquen, o estudien la posibilidad de dedicarse, a actividades políticas, tengan en cuenta la forma en que tal dedicación podría afectar -o parecer que afecta- su capacidad de desempeñar con imparcialidad sus obligaciones profesionales. Si los auditores están autorizados a participar en actividades políticas, tienen que ser conscientes de que tales actividades pueden provocar conflictos profesionales.

\section{Conflictos de intereses}

22. Cuando los auditores están autorizados a asesorar o a prestar servicios distintos de la auditoría a una entidad fiscalizada, hay que procurar que estos servicios no lleven a un conflicto de intereses. En particular, los auditores deben garantizar que dichos servicios o asesoramiento no incluyan responsabilidades o facultades de gestión, que deben continuar desempeñando con claridad los directivos de la entidad fiscalizada.

23. Los auditores deberán proteger su independencia y evitar cualquier posible conflicto de intereses rechazando regalos o gratificaciones que puedan interpretarse como intentos de influir sobre la independencia y la integridad del auditor.

24. Los auditores deben evitar toda clase de relaciones con los directivos y el personal de la entidad fiscalizada y otras personas que puedan influir, comprometer o amenazar la capacidad de los auditores para actuar y parecer que actúan con independencia.

25. Los auditores no deberán utilizar su cargo oficial con propósitos privados y deberán evitar relaciones que impliquen un riesgo de corrupción o que puedan suscitar dudas acerca de su objetividad e independencia.

26. Los auditores no deberán utilizar información recibida en el desempeño de sus obligaciones como medio de obtener beneficios personales para ellos o para otros. Tampoco deberán divulgar informaciones que otorguen ventajas injustas o injustificadas a otras personas u organizaciones, ni deberán utilizar dicha información en perjuicio de terceros.

\section{Capítulo IV Secreto profesional}

27. La información obtenida por los auditores en el proceso de auditoría no deberá revelarse a terceros, ni oralmente ni por escrito, salvo a los efectos de cumplir las responsabilidades legales o de otra 
clase que correspondan a la EFS, como parte de los procedimientos normales de ésta, o de conformidad con las leyes pertinentes.

\section{Capítulo V \\ Competencia profesional}

28. Los auditores tienen la obligación de actuar en todo momento de manera profesional y de aplicar elevados niveles profesionales en la realización de su trabajo con objeto de desempeñar sus responsabilidades de manera competente y con imparcialidad.

29. Los auditores no deben llevar a cabo trabajos para los que no posean la competencia profesional necesaria.

30. Los auditores deben conocer y cumplir las normas, las políticas, los procedimientos y las prácticas aplicables de auditoría, contabilidad y gestión financiera. De igual modo, deben entender adecuadamente los principios y normas constitucionales, legales e institucionales que rigen el funcionamiento de la entidad fiscalizada.

\section{Desarrollo profesional}

31. Los auditores deben ejercer la profesionalidad debida en la realización y supervisión de la auditoría y en la preparación de los informes correspondientes.

32. Los auditores deben emplear métodos y prácticas de la máxima calidad posible en sus auditorías. En la realización de la auditoría y la emisión de informes, los auditores tienen la obligación de ajustarse a los postulados básicos y a las normas de auditoría generalmente aceptadas.

33. Los auditores tienen la obligación continuada de actualizar y mejorar las capacidades requeridas para el desempeño de sus responsabilidades profesionales.

\section{Código de Ética del Auditor Gubernamental de la Contraloría General de la República \\ (Aprobado por Resolución de Contraloría N 077-99-CG)}

\section{Preámbulo}

La Contraloría General de la República, es consciente de que los auditores gubernamentales estamos rodeados de un entorno dinámico, que caracteriza a nuestra Administración Pública, por lo que resulta necesario contar con referentes visibles y continuados que permitan orientar nuestras conductas, a la vez que apreciar y demostrar lo positivo de nuestro desempeño, a fin de honrar, la credibilidad y confianza pública sobre nuestro desempeño;

Que, el Sistema Nacional de Control, considera que en la función pública no resulta suficientemente meritorio un buen cumplimiento de las funciones confiadas por la sociedad sino se encuentra sustentado en la observancia de sólidos principios éticos;

Que, como receptores de la milenaria tradición andina, debemos asumir la actualidad de su norma ama sua, ama quella, ama llulla ("no seas ladrón, no seas flojo, no seas mentiroso"), como guía de conducta; Que, dentro de este contexto, resulta adecuado adoptar con carácter vinculante un conjunto específico de normas mínimas que constituyan las guias de orientación para que el auditor las examine, aprecie y aplique, en cualquier circunstancia, que se encuentren en sus actuaciones concretas durante el ejercicio de su cometido, sin excluir las normas de conducta señaladas en los diversos Colegios Profesionales al cual se pertenezca.

Por ello, a continuación reunimos las exigencias éticas cuya forma y_espíritu deben ser tomadas en cuenta permanentemente por todos los que desempeñamos la auditoría gubernamental; quienes no sólo debemos reflexionar privadamente acerca de su cumplimiento y de si nuestras actitudes cotidianas resultan compatibles con ellos, sino también si nuestros actos u omisiones motivan a que otros racionalmente puedan cuestionar tal performance ética.

\section{Aptitud de Servicio}

Siendo consecuentes con nuestra elección individual de laborar en el Sistema Nacional de Control asumimos la aptitud permanente para desempeñar las actividades que se nos encomienden o disponer, con 
sostenida iniciativa y diligencia, la realización de aquéllas que correspondan conforme a las disposiciones vigentes, involucrándonos activamente en su cometido.

La vocación de servicio se muestra en acciones de entrega diligente a las tareas asignadas, en la disposición para dar esmerada atención a los requerimientos y trabajos encomendados, en tener receptividad para atender y solucionar las peticiones, denuncias o quejas de los ciudadanos.

\section{Calidad de servicio}

Propender a que nuestras acciones produzcan mejoras continuas en nuestras instituciones y contribuyan al logro de la excelencia en el servicio público, por medio de nuestras recomendaciones y de la información confiable, útil, oportuna y con valor agregado que reportamos.

Para dicho fin, somos conscientes de:

a) La necesidad de mantener el entrenamiento continuo;

b) Ser receptivos a las observaciones y sugerencias que para el mejoramiento de nuestro desempeño nos sean formulados por los compañeros y superiores, así como con las medidas de control de calidad del Sistema Nacional de Control;

c) La necesidad de agotar todos los medios necesarios para cumplir nuestras responsabilidades, así como para alcanzar las metas, objetivos y la expectativa técnica perseguida por nuestra acción.

\section{Compromiso con el país}

Nuestras acciones se encuentran orientadas al bienestar del pais, y a propiciar el desarrollo de una Administración Pública al servicio de la sociedad, para lo cual estamos comprometidos con los intereses permanentes de nuestras instituciones, con la salvaguarda del patrimonio público y con el respeto estricto al ordenamiento jurídico y demás deberes del Estado, subordinando a ellos, los intereses individuales.

\section{Cordialidad}

Durante todo proceso de auditoría, las tareas se desempeñan teniendo en cuenta los derechos y la dignidad de los auditados, la necesaria eficiencia y eficacia en la administración de recursos, así como la continuidad del servicio de las áreas examinadas; por lo que observamos las reglas de buena conducta con los funcionarios públicos sin poner en riesgo nuestra independencia y probidad, y evitamos cualquier exceso de atribuciones que cree un clima inadecuado para nuestra labor.

\section{Cuidado y esmero profesional}

Los auditores permanentemente somos cuidadosos en emplear correctamente el juicio profesional para determinar y elegir cada una de las decisiones propias de nuestra actividad, así como para premunirnos de todos aquellos elementos y criterios imprescindibles para poder decidir nuestros cursos de acción.

\section{Independencia, objetividad e imparcialidad}

Los auditores reconocemos la independencia como un factor esencial para un mejor desempeño, por lo que nuestras decisiones y actuaciones siempre se orientan a aumentar los niveles de independencia y no a disminuirla.

Al desempeñar nuestras tareas nos encontramos guiados por la exactitud, rectitud e imparcialidad, como garantías mínimas de objetividad, por lo que damos un tratamiento igualitario a todos los auditados, analizamos los hechos alejados de cualesquier predisposición o preferencia acerca de las personas o entidades y anteponiendo los criterios técnicos y la evidencia a cualesquier otra circunstancia.

Nos encontramos permanentemente atentos a proteger nuestra independencia; evitando cualquier situación o relación personal que pueda implicar un riesgo de corrupción, suscitar dudas acerca de la independencia requerida, o incurrir en interés personal en conflicto con las tareas que nos han sido 
confiadas. Del mismo modo, estamos prestos a declinar cortés, pero firmemente, cualquier intento de influencia que pretendiera ejercerse sobre nuestras acciones, por más sutil que sea.

\section{Probidad administrativa}

En lo personal, mantenemos una conducta intachable, en nuestras decisiones, al administrar los bienes y recursos públicos, con entrega leal y honesta al desempeño de nuestras tareas, siendo conscientes y respetando por tanto, las limitaciones, restricciones y abstenciones que ellas nos exigen. Reconocemos que nuestra conducta debe ser irreprochable en todo momento, procurando adoptar siempre el comportamiento que quisiéramos que siguiera cualesquier funcionario público ejemplar; ya que aún una pequeña deficiencia perjudica la imagen de integridad y calidad de la labor de quienes ejercen la auditoría gubernamental y del Sistema Nacional de Control.

A través, de nuestro ejercicio funcional, colaboramos con la probidad pública, comunicando aquellos hechos que denotan irregularidades o fraudes de modo oportuno y con el mayor sustento posible, para permitir su comprensión exacta y esclarecimiento por la instancia que corresponda.

\section{Reserva o confidencialidad}

Quienes asumimos las actividades inherentes a la auditoría gubernamental, aún luego de concluir éstas, tenemos la obligación personalísima de guardar reserva respecto a sus programas, procesos y resultados, así como sobre la información privilegiada, de la cual tomáramos conocimiento con motivo de este ejercicio, estando impedido de utilizarlas, revelarlas o transmitirlas a terceros de cualquier modo, salvo a efectos de cumplir con nuestras responsabilidades legales.

\section{Tecnicismo}

Actuamos en todo momento de manera profesional, aplicando los estándares profesionales internacionales, las normas de auditoría gubernamental, la capacidad profesional y la madurez de criterio que nos demanda la trascendente labor del control gubernamental; y formulamos nuestras opiniones objetivamente con prescindencia de cualesquier incidencia o efecto que su ejecución o sus resultados puedan derivar para el poder público o grupos interesados.

\section{Vocación por la verdad y la transparencia}

En todas nuestras actividades transmitimos, con la convicción que nos otorga la seguridad en la corrección de nuestra labor, los resultados veraces y opiniones ciertas que hayan sido reveladas y evidenciadas, sin ocultamientos, ni ambigüedades. Para tal efecto asumimos una conducta transparente durante nuestro ejercicio funcional, que implica particularmente:

a) Generar y transmitir información útil, pertinente, comprensible, fiable y verificable para la toma de decisiones.

b) Brindar información sobre nuestras operaciones a quienes se encuentran facultados para apreciarlas o evaluarlas, así como permitir y preservar su acceso.

c) Manifestar con claridad e integridad las recomendaciones, y las opiniones que nos competen.

d) Presentar las declaraciones juradas de bienes y rentas que nos competen conforme a ley.

\section{Declaración final}

Los auditores gubernamentales, declaramos que como ciudadanos respaldamos el cumplimiento de este Código de Ética, con una vida privada moralmente íntegra y decorosa, y que valoramos el servicio a la sociedad, por medio de la auditoría, como una forma trascendente de realización personal. 